STUDI

FRANCESI

\section{Studi Francesi}

Rivista quadrimestrale fondata da Franco Simone

168 (LVI | III) | 2012

Varia

\title{
La Polémique contre la modernité. Antimodernes et réactionnaires, études réunies par Marie-Catherine Huet-Brichard et Helmut Meter
}

Michel Arrous

\section{CpenEdition}

Journals

Édition électronique

URL : http://journals.openedition.org/studifrancesi/3752

DOI : 10.4000/studifrancesi.3752

ISSN : 2421-5856

Éditeur

Rosenberg \& Sellier

Édition imprimée

Date de publication : 1 décembre 2012

Pagination : $572-573$

ISSN : 0039-2944

Référence électronique

Michel Arrous, "La Polémique contre la modernité. Antimodernes et réactionnaires, études réunies par Marie-Catherine Huet-Brichard et Helmut Meter », Studi Francesi [En ligne], 168 (LVI | III) | 2012, mis en ligne le 30 novembre 2015, consulté le 05 mars 2021. URL : http://journals.openedition.org/ studifrancesi/3752 ; DOI : https://doi.org/10.4000/studifrancesi.3752

Ce document a été généré automatiquement le 5 mars 2021.

\section{cc) (†) $\odot$}

Studi Francesi è distribuita con Licenza Creative Commons Attribuzione - Non commerciale - Non opere derivate 4.0 Internazionale. 


\title{
La Polémique contre la modernité. Antimodernes et réactionnaires, études réunies par Marie-Catherine Huet- Brichard et Helmut Meter
}

\author{
Michel Arrous
}

\section{RÉFÉRENCE}

AA. VV., La Polémique contre la modernité. Antimodernes et réactionnaires, études réunies par Marie-Catherine HUET-BRICHARD et Helmut METER, Paris, Classiques Garnier, 2011, pp. 361.

1 Et si les vrais modernes étaient les antimodernes? Ou, comme l'a proposé Antoine Compagnon, des non-conformistes de la modernité? C'est cette définition qu'ont retenue dans leur Introduction (pp. 7-11) Marie-Catherine HUET-BRICHARD et Helmut METER, tout en reconnaissant qu'il est difficile de préciser la physionomie de ces réfractaires. La caractéristique la plus évidente des antimodernes, c'est bien sûr leur lutte contre l'optimisme rationaliste ou la philosophie du progrès, ce "paganisme des imbéciles» (Baudelaire). De ces vingt études qui couvrent plus de deux siècles, puisqu'il est aussi question de ces antimodernes et postmodernes que sont Philippe Murray, Richard Millet, Valère Novarina et Claude Régy, on ne retiendra que celles concernant le XIX ${ }^{\mathrm{e}}$ et le début du XX⿳亠丷厂犬⿱

Situant son propos Après les antimodernes (pp. 13-23), Antoine COMPAGNON, qui rappelle que les antimodernes ne sont pas simplement des conservateurs, des réactionnaires, des traditionalistes, des académiques ou des néo-classiques, et que l'on peut discuter la place de tel ou tel dans la liste, propose un supplément à ses Cinq Paradoxes de la modernité (1989): «les vrais modernes sont des antimodernes, c'est-à-dire des modernes lucides, non dupes du moderne». Les vrais antimodernes d'aujourd'hui s'opposeraient à la doxa antimoderne et revendiqueraient la défense des Lumières. 
3 Le père dont se réclament la plupart des antimodernes, c'est Joseph de Maistre. Plutôt que de revenir sur sa mise en cause radicale de l'idéologie moderne, Pierre GLAUDES a préféré Une idée antimoderne: la réversibilité (pp. 25-39). De juridique à son origine, ce concept devient théologique dans le mécanisme sacrificiel de Maistre. Il fera débat: alors que Vigny, Lamartine et Hugo le jugeront un dangereux sophisme, Baudelaire, Barbey d'Aurevilly, Bloy et Bernanos en feront un argument contre leur siècle. On ne s'étonnera pas de voir Stendhal au nombre des antimodernes, même s'il s'agit d'un antimoderne modéré qui corrige le moderne. Helmut MEYER l'illustre de manière restreinte dans Ethnographie comparée de Stendhal. La dichotomie entre moderne et antimoderne dans "Rome, Naples et Florence" (1826) (pp.41-60). Dans son apologie de l'archaïsme de l'Italie, on peut lire une critique indirecte de la modernité, par exemple quand il évoque le rôle dominant de la passion chez les gens du Sud, ou bien celui de la femme italienne. Pour Stendhal, l'Italie est «le pays paradigmatique pour observer et comprendre la dialectique entre moderne et antimoderne». Avec le pessimiste Balzac et sa conception d'une société hiérarchisée, on a affaire à l'antimoderne moderne. Cependant, comme l'écrit Willi JuNG (Balzac ou la polémique d'un antimoderne moderne, pp.61-73), Balzac «n'est pas assez rétrograde pour prendre la défense de l'ordre existant tel qu'il est». Ce sont les relations conflictuelles de Baudelaire avec la modernité que retrace Jérôme SolAL dans Une histoire belge: Baudelaire et la guerre à (la) répétition (pp. 75-91). Une fois en Belgique, l'inventeur et contempteur de la modernité aiguise ses griffes contre la France, en fait contre l'identité moderne grosse d'une catastrophe, en s'en prenant à la Belgique dans laquelle il voit la «version micro de la modernité, comme l'Amérique en est la version macro».

4 Après avoir rappelé qu'on ne naît pas antimoderne mais qu'on le devient, Jean-Marc SEILLAN retrace le parcours de l'auteur d'À Rebours: une première période marquée par la virulence contre Falloux, Ozanam ou Veuillot puis, après la conversion, la vis polemica ne s'atténue pas chez le chrétien désemparé (Huysmans polémiste antimoderne. Du front de gauche au front de droite, pp.93-109). Sonneur de tocsin seul contre tous, Bloy est l'antimoderne d'élite qui voulut «dire la vérité quand même et toujours sans consulter [s]on intérêt» (lettre à sa sœur, 1874). Pour illustrer cette stratégie discursive, Bernard GALLINA (Léon Bloy, "Belluaires et porchers", un cas de polémique antimoderne, pp. 111-124) a retenu les thèmes de la contre-révolution, des anti-Lumières, du péché originel, venus tout droit de Maistre dont la véhémence se retrouve dans la vitupération habituelle à Bloy. Fabienne BERCÉGOL s'est proposé d'étudier la façon dont a été lu et apprécié Chateaubriand, ou comment son choix d'«avancer dans le sens de l'histoire en dépit de l'attachement au passé» a conditionné les jugements portés sur son action, souvent controversée, même par ceux qui auraient pu se réclamer de ses idées: La réception polémique de l'œuvre de Chateaubriand chez les antimodernes (pp.125-143). Le procès commença avec Barbey qui lui reprocha d'être un fils des Lumières et surtout d'avoir voulu être un médiateur entre l'Ancien Régime et les aspirations nées de la Révolution. Le discrédit jeté sur son action politique est aggravé par le jugement porté sur son pessimisme existentiel - Barrès parlera de «nihilisme» - que Barbey juge contradictoire à l'ambition d'intervenir dans l'Histoire. Lui emboîtant le pas, Maurras reprochera au Génie du christianisme un manque de sérieux dans l'apologétique et condamnera lui aussi son action politique. Toutes idées qu'on retrouve dans Le Grand Paon de Julien Gracq (1960). 
5 Le cas Léon Daudet ne serait-il pas celui d'un traditionaliste? Peut-on distinguer l'écriture polémique d'un traditionaliste de celle d'un antimoderne? En posant ces questions, Marie-Catherine HUET-BRICHARD signale, dans "Le Stupide XIX siècle": antimodernes et traditionalistes (pp. 145-160), que la représentation du siècle à rebours de Daudet n'apporte guère de nouveau après Maistre, Bonald ou Maurras. Certes, son style ne manque pas d'allure quand il s'en prend aux «idoles» d'une époque tombée sur la tête: pour asséner ses vérités, le traditionaliste pratique tous les modes de l'éreintement, n'hésitant pas à défier les bonnes manières, voire à recourir à la trivialité. Mais à la différence des antimodernes nostalgiques d'un temps à jamais révolu, le traditionaliste, tel Daudet et l'Action française, prétend possible le retour en arrière. Le traditionaliste Daudet serait un "antimoderne repenti». On retrouve son antiromantisme - qui ne l'empêchait pas d'admirer le romantisme antimoderne de Baudelaire et de Barbey - chez cet autre traditionaliste que fut Maurras. Le thuriféraire du génie «roman» au classicisme réactif qui reconnaissait dans la tradition un remède à l'absurdité de l'existence, est-il un traditionaliste? Jean-Yves PrANCHÈre le voit en antimoderne ou faux traditionaliste qui accepte la modernité positiviste: Un "romantisme du positivisme?" Les ambiguïtés de l'antiromantisme de Charles Maurras (pp. 161-179). Disciple de Comte - quoiqu'il rejetât la croyance au progrès de l'histoire et au progrès par la science - le critique Maurras ne ménagea ni les parnassiens ni les symbolistes et prôna la discipline classique comme remède à la nostalgie romantique, gardant en lui l'élan d'un romantisme dépouillé des illusions du moi. D'où son attitude ambiguë face à Nietzsche en qui il voit un romantique en révolte contre le romantisme. Dans Maurice Barrès: un antimoderne malgré lui? (pp. 181-192), Vital RAMBAUD se dresse en faux contre une récente tradition universitaire faisant de Barrès un moderne. Barrès prit d'abord le parti de la modernité et du cosmopolitisme pour, finalement et bien banalement, devenir un antimoderne qui n'abjura pas tous les choix de sa jeunesse. Parmi les choix antimodernes qu'entraîna sa conversion au nationalisme et son culte de la Terre et des Morts, V. Rambaud mentionne l'antisémitisme, dès avant l'affaire Dreyfus, les attaques contre les programmes scolaires de la $\mathrm{III}^{\mathrm{e}}$ République et les mauvais maîtres de la Sorbonne, contre les prétentions universalistes des intellectuels, mais aussi le procès intenté à Rousseau auquel il préféra Pascal, suivant en cela «le chemin habituel de l'antimoderne» (A. Compagnon). Mais à la différence de Maurras, Barrès ne condamna ni la Révolution ni le parlementarisme, de plus, à la différence de Maurras, Léon Daudet et Pierre Lasserre, il ne condamna jamais le romantisme et encore moins le XIX ${ }^{e}$ siècle. Barrès n'a cessé de s'interroger quant à sa situation par rapport à la modernité.

6 Cette dizaine d'exemples confirme qu'il n'y a pas de modèle immuable de l'antimoderne et que l'antimodernité trouve son origine dans la Révolution ou, pour beaucoup des antimodernes du XIXe siècle, dans la détestation de 1789. Une constante: tous attaquent les valeurs de l'univers bourgeois. 